\title{
Resistance Exercise Modulates Oxidative Stress Parameters and TNF- $\alpha$ Content in the Heart of Mice with Diet-Induced Obesity
}

\author{
Pauline Souza Effting, ${ }^{1 \oplus}$ Stella M. S. Brescianini, ${ }^{10}$ Helen R. Sorato, ${ }^{1 \oplus}$ Bruna Barros Fernandes, ${ }^{10}$ Giulia dos S. \\ Pedroso Fidelis, ${ }^{10}$ Paulo Roberto L. da Silva, ${ }^{10}$ Paulo César L. Silveira, ${ }^{1,40}$ Renata T. Nesi, ${ }^{10}$ Rolando B. Ceddia, ${ }^{3(0)}$ \\ Ricardo A. Pinho 1,2 \\ Laboratório de Fisiologia e Bioquímica do Exercício (LAFIBE) - Programa de Pós-Graduação em Ciências da Saúde (PPGCS) - Universidade do \\ Extremo Sul Catarinense (UNESC), ${ }^{1}$ Criciúma, SC - Brazil \\ Laboratório de Bioquímica do Exercício em Saúde (BioEx) - Programa de Pós-Graduação em Ciências da Saúde (PPGCS) - Pontifícia \\ Universidade Católica do Paraná (PUCPR), ${ }^{2}$ Curitiba, PR - Brazil \\ Muscle Health Research Center, School of Kinesiology and Health Center - York University, ${ }^{3}$ Toronto, ON - Canadá \\ Laboratório de Fisiopatologia Experimental - Programa de Pós-Graduação em Ciências da Saúde (PPGCS) - Universidade do Extremo Sul \\ Catarinense (UNESC), ${ }^{4}$ Criciúma, SC - Brazil
}

\section{Abstract}

Background: Obesity can be characterized by low-grade chronic inflammation and is associated with an excess production of reactive oxygen species, factors that contribute to coronary heart disease and other cardiomyopathies.

Objective: To verify the effects of resistance exercise training on oxidative stress and inflammatory parameters on mice with obesity induced by a high-fat diet (HFD).

Methods: 24 Swiss mice were divided into 4 groups: standard diet (SD), SD + resistance exercise (SD + RE), diet-induced obesity (DIO), DIO + RE. The animals were fed SD or HFD for 26 weeks and performed resistance exercises in the last 8 weeks of the study. The insulin tolerance test (ITT) and body weight monitoring were performed to assess the clinical parameters. Oxidative stress and inflammation parameters were evaluated in the cardiac tissue. Data were expressed by mean and standard deviation $(p<0.05)$.

Results: The DIO group had a significant increase in reactive oxygen species levels and lipid peroxidation with reduction after exercise. Superoxide dismutase and the glutathione system showed no significant changes in DIO animals, with an increase in SD + RE. Only catalase activity decreased with both diet and exercise influence. There was an increase in tumor necrosis factor-alpha (TNF- $\alpha$ ) in the DIO group, characterizing a possible inflammatory condition, with a decrease when exposed to resistance training (DIO+RE).

Conclusion: The DIO resulted in a redox imbalance in cardiac tissue, but the RE was able to modulate these parameters, as well as to control the increase in TNF- $\alpha$ levels. (Arq Bras Cardiol. 2019; 112(5):545-552)

Keywords: Exercise; Oxidative Stress; Obesity; Diet, High-Fat; Mice.

\section{Introduction}

The World Health Organization (WHO $)^{1}$ defines obesity as an abnormal or excessive accumulation of fat that brings health risks. The WHO brings data from the Global Health Observatory showing a worldwide prevalence of obesity of $39 \%$ in men and women over 18 years of age (2016 updated data). In this scenario, obesity is also a risk factor for lifestyle-related diseases, such as cardiovascular disease and type 2 diabetes mellitus. ${ }^{2}$ It can be characterized by low-grade chronic inflammation and is associated with increased levels of proinflammatory cytokines, as well as an excess production of reactive oxygen species. ${ }^{3,4}$

Studies have shown that hyperglycemia and alterations in glucose uptake in diabetes may lead to oxidative stress with consequent mitochondrial dysfunction, as well as to

Mailing Address: Pauline Souza Effting •

Rua Alda Agliardi Colombo, 210. Postal Code 88816-735, Pedro Zanivan, Criciúma, SC - Brazil

E-mail: paulinese@gmail.com, paulinese@outlook.com

Manuscript received May 29, 2018, revised manuscript August 20, 2018, accepted October 02, 2018

DOI: $10.5935 /$ abc. 20190072 an inflammatory process with the presence of elevated proinflammatory cytokines, such as TNF- $\alpha$. Both cases may be triggering factors for coronary heart disease and other cardiomyopathies $^{5}$ (see review by Adeghate and Singh). Gamez-Mendez et al., ${ }^{6}$ also showed that 8 weeks of high-fat diet (HFD) led to an increase in oxidative stress, resulting in an imbalance of vasoactive substances and consequent endothelial dysfunction of the coronary arteries in obese rats.

Studies point to physical exercise as an important ally in reducing the risks related to obesity due to its ability to reestablish the balance between pro-anti-inflammatory cytokines and regulate the cell redox state. ${ }^{7,8}$ According to Boardman et al., ${ }^{9}$ physical exercise is not only an important therapeutic approach in obesity, but it is also crucial for cardiac function improvement and ischemic injury prevention in obese and/or diabetic animals.

Although the literature indicates that exercise is important to prevent or complement the treatment of obesity, ${ }^{10}$ one should consider the characteristics of the performed exercise, such as: intensity, duration, frequency and type.

Based on the aforementioned facts, this study aimed to identify whether resistance exercise (RE) modifies the oxidative stress and inflammation parameters caused by an HFD in an experimental model of obesity. 


\section{Methods}

\section{Animals}

Male Swiss mice (40 days), obtained at the vivarium of Universidade do Extremo Sul Catarinense - UNESC (Criciúma/ SC - Brazil), with an average weight of $35.45 \mathrm{~g}( \pm 1.29)$ were studied. The animals were kept at a 12/12h light/dark cycle at $22^{\circ} \mathrm{C}$ in collective boxes ( 6 animals per box) and randomly divided into four groups $(n=6)$ : standard diet $(\mathrm{SD})$; diet-induced obesity (DIO); SD + RE; DIO + RE. The random selection procedure was carried out by arbitrarily or randomly allocating the animals to the respective groups, without prior performance evaluation or using any other indicator that allowed the groups to be divided.

\section{Diet}

The animals were fed ad libitium for 26 weeks with low-fat SD (SD: $27 \%, 23 \%$ and $50 \%$ of calories from proteins, fats and carbohydrates, respectively - 3.3kcal/g) or HFD (HFD: 15\%, $59 \%$ and $26 \%$ of calories from proteins, fats and carbohydrates, respectively $-5.3 \mathrm{kcal} / \mathrm{g}$ ). The SD was purchased from the Puro Trato Nutrição Animal (Puro Lab 22PB) Santo Augusto/RS - Brazil, and the HFD from PragSoluções Biociência, Jaú/SP - Brazil.

\section{Exercise}

The exercise adaptation protocol was started in the $17^{\text {th }}$ week of the diet and the RE protocol in the $18^{\text {th }}$. The resistance training was performed in a $1-\mathrm{m}$ ladder apparatus with $2 \mathrm{~cm}$ steps and $85^{\circ}$-slope. ${ }^{11}$ The animals were familiarized with the climbing exercise on the steps for 5 consecutive days without load. The training protocol, adapted from Scheffer et al., ${ }^{12,13}$ started 3 days after the last adaptation training, and was performed with a 48-h interval between sessions, for 8 weeks, totaling 28 training sessions. The exercise was performed with intensity progression by adding a weight to the animal's tail (load increase of $20 \%$ to $75 \%$ of body weight), and volume progression (5-10 series per session) (Table 1), with a 2-min interval between sessions in the rest area (closed box at the top of the steps measuring $20 \times 20 \times 20 \mathrm{~cm}$ ). Each series was performed until the animals completed 5 repetitions/climbings (without interval), or

\section{Table 1 - Resistance training protocol}

\begin{tabular}{lccc}
\hline Weeks & Load & Series & Interval between series \\
\hline $1^{\text {st }}$ & $20 \%$ & 5 & $1(2 \mathrm{~min})$ \\
$2^{\text {nd }}$ & $20 \%$ & 7 & $1(2 \mathrm{~min})$ \\
$3^{\text {rd }}$ & $50 \%$ & 5 & $1(2 \mathrm{~min})$ \\
$4^{\text {th }}$ & $50 \%$ & 7 & $1(2 \mathrm{~min})$ \\
$5^{\text {th }}$ & $50 \%$ & 10 & $1(2 \mathrm{~min})$ \\
$6^{\text {th }}$ & $50 \%$ & 10 & $1(2 \mathrm{~min})$ \\
$7^{\text {th }}$ & $75 \%$ & 7 & $1(2 \mathrm{~min})$ \\
$8^{\text {th }}$ & $75 \%$ & 10 & $1(2 \mathrm{~min})$ \\
\hline
\end{tabular}

Source: Study data. Adapted from Scheffer et al. ${ }^{12}$ could not climb the stairs even after encouragement (manual stimulation at the base of the tail).

\section{Body weight and insulin tolerance test (ITT)}

Individual body weight was measured at the start of the study and at weeks 3, 6, 10, 14, 18, 22 and 26. After 17 weeks on the diet, an ITT was performed to confirm insulin resistance. After 6 hours of fasting, ${ }^{14}$ all animals received a dose of $2 \mathrm{U} / \mathrm{kg}$ of insulin. Blood glucose was measured with a glycometer using a drop of blood collected from a small incision at the tip of the animal's tail. The same protocol was performed at the end of the experiment, 48 hours after the last exercise session.

\section{Euthanasia}

$24 \mathrm{~h}$ after the last insulin tolerance test, euthanasia by decapitation was performed and the left ventricle of the heart was surgically extracted, immediately frozen in liquid nitrogen, and stored at $-80^{\circ} \mathrm{C}$ for biochemical analysis.

\section{Biochemical analyses}

For the biochemical assays described below and ELISA test, all samples were homogenized in $50 \mathrm{mM}$ phosphatebuffered saline (PBS), with the addition of 10uM aprotinin. The homogenate was centrifuged for $10 \mathrm{~min}$ at $4^{\circ} \mathrm{C}$ and the supernatant was stored at $-80^{\circ} \mathrm{C}$. Protein levels were determined in all samples using the Bradford method. ${ }^{15}$

\section{Oxidation of dichlorodihydrofluorescein (DCFH)}

Reactive species levels were measured based on oxidation of the 2',7'-dichlorodihydrofluorescein diacetate (DCFH-DA) probe in a fluorescent 2',7'-dichlorodihydrofluorescein (DCF) compound as previously described. ${ }^{16}$ An aliquot of the lysate was incubated with $80 \mathrm{mM}$ DCFH-DA at $37^{\circ} \mathrm{C}$ for 15 minutes. The production of reactive species was quantified using a standard DCF curve and data were expressed as $\mathrm{nM}$ DCF/mg protein.

\section{Antioxidant enzyme activity}

The superoxide dismutase (SOD) activity was estimated by inhibiting the auto oxidation of adrenaline and read spectrophotometrically at $480 \mathrm{~nm}$ according to the method described by McCord and Fridovich. ${ }^{17}$ Catalase (CAT) activity was established based on the rate of hydrogen peroxide $\left(\mathrm{H}_{2} \mathrm{O}_{2}\right)$ decomposition, generated by the enzyme present in the sample using a $10 \mathrm{mM} \mathrm{H}_{2} \mathrm{O}_{2}$ solution in potassium phosphate buffer with $\mathrm{pH}$ of 7.0 . The maximum rate of $\mathrm{H}_{2} \mathrm{O}_{2}$ decomposition was measured at $240 \mathrm{~nm} .{ }^{18}$ Values were expressed as units of SOD or CAT per mg of protein.

\section{Total glutathione (GSH) levels}

GSH levels were measured using the Hissin method. ${ }^{19}$ Samples were incubated in $0.6 \%$ sulfosalicylic acid followed by a reaction of the GSH present in the sample with 2-nitrobenzoic acid (5,5'-Dithiobis) (DTNB) producing an oxidized glutathione-TNB adduct (GS-TNB). The resulting 
color from the reaction between the DTNB and thiols compared to the standard curve for GSH was kinetically established at $412 \mathrm{~nm}$ for $10 \mathrm{~min}$. Values were expressed as $\mathrm{nmol} / \mathrm{min} / \mathrm{mg}$ protein.

\section{Lipoperoxidation}

The concentrations of malondialdehyde (MDA) in the samples were determined by high-performance liquid chromatography (HPLC) (Agilent Technologies 1200 Series; Santa Clara, CA, USA), according to Grotto et al. (2007) $)^{20}$ using a derivative of thiobarbituric acid (TBA). A standard curve was created using MDA tetrabutylammonium salt at concentrations ranging from 0.5 to $5 \mu \mathrm{mol} / \mathrm{L}$. The MDA was determined at $532 \mathrm{~nm}$ and the results were expressed as umol/L of MDA/milligram protein.

\section{Inflammatory Parameter}

The concentration of tumor necrosis factor-alpha (TNF- $\alpha$ ) was assessed by enzyme-linked immunosorbent assay (ELISA) according to the manufacturer's recommendations (ThermoFisher Scientific, cat.KMC3011). The results were expressed in $\mathrm{pg} / \mathrm{mg}$ of protein.

\section{Statistical analysis}

Initially, the data were assessed using Grubbs test to verify possible outliers followed by the Shapiro-Wilk normality test, and in both of them the data met the assumptions for the use of parametric tests. Then, the Two-way ANOVA test was performed, followed by the Bonferroni post-hoc test when necessary. For analysis of the ITT data (table 2), the one-way variance test (one-way ANOVA) of repeated measures was performed, followed by post-hoc Tukey test when necessary. The level of significance was set at $p<0.05$. The Graph Pad Prism software, version 5, was used as the statistical package. All data were expressed as mean and standard deviation, except for figure $1 \mathrm{~A}$, expressed as mean and standard error of mean.

\section{Results}

\section{Body weight and insulin resistance}

The RE had a beneficial effect, preventing the DIO + RE group from continuing to gain weight even with the HFD consumption, not characterizing weight loss, but rather weight maintenance, even without food intake control (Figure 1A-C).

The pre-exercise ITT showed that the DIO animals had insulin resistance $(p>0.05)$ (Table 2$)$. The results demonstrated that HFD can lead to a loss of glucose uptake even with an external insulin stimulus ( $2 \mathrm{U} / \mathrm{kg}$ body weight). The RE ( $p<0.05)$, even with HFD intake, was able to delay the progression of the disease, maintaining a better glucose decay rate when compared to the sedentary DIO group $(p<0.01)$. There was no significant difference between preand post-exercise in any group (Figure 1D).

\section{DCFH oxidation}

DCFH oxidation levels were measured as indicators of the reactive species production, especially hydrogen peroxide, and the results showed that in untrained animals, DIO caused an increase in DCF levels $(p<0.001)$ in comparison to animals with SD. HFD-fed animals submitted to resistance training $(\mathrm{DIO}+\mathrm{RE})$ showed a significant decrease in DCF levels compared to the DIO group $(p<0.01)$ (Figure 2A).

\section{Lipoperoxidation}

As shown in Figure 2B, MDA levels suggest an increase in lipoperoxidation in DIO animals $(p<0.05)$, with reversion of the condition $(p<0.05)$ with resistance training $(D I O+R E)$.

\section{SOD Activity}

The results observed in Figure $2 \mathrm{C}$ show that $\mathrm{DIO}$ did not alter SOD activity, but resistance training was able to increase its activity in the SD + RE group ( $p<0.05)$, an increase not observed when exercise was performed in the obese group.

Table 2 - Insulin tolerance test (ITT) - blood glucose curve

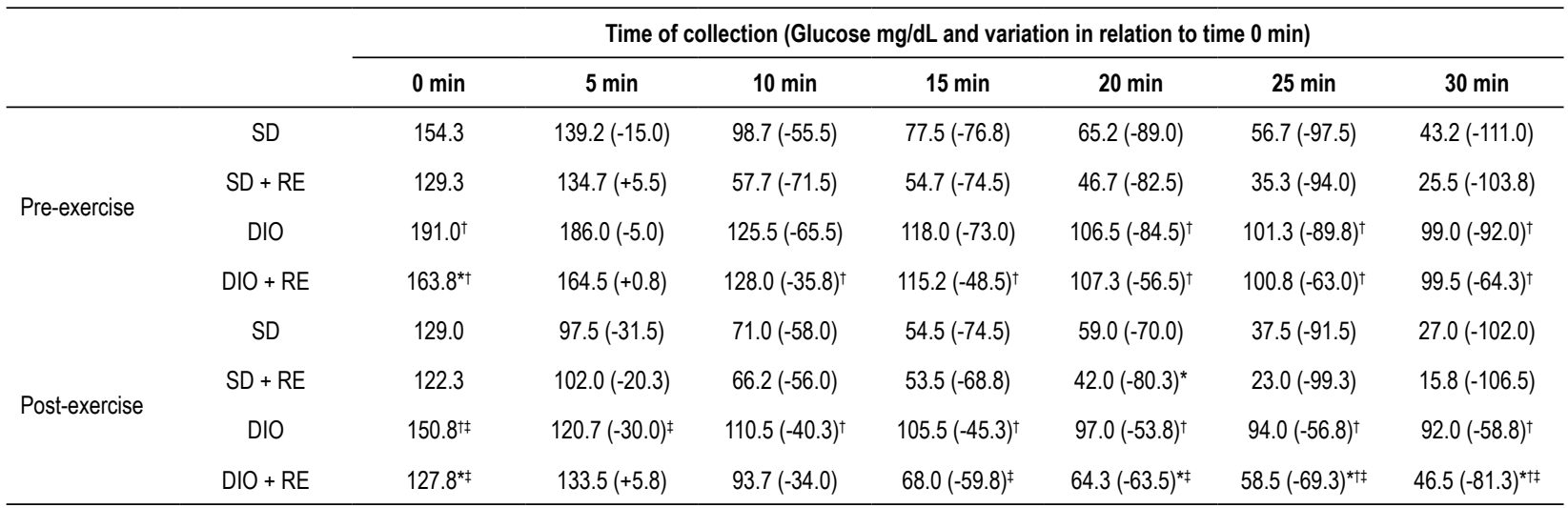

Source: study data. Pre-adaptation/exercise (week 17) and post-exercise (week 26). Blood glucose was measured after 6 hours of fasting (data from the table) at times $0 \mathrm{~min}$ (baseline), followed by an intraperitoneal insulin injection (2 U/kg) and measurements at times $5-30$ min. ${ }^{*} p<0.05$ versus respective untrained; ${ }^{\dagger} p<0.05$ versus respective standard diet; $\neq p<0.05$ versus respective pre-exercise. SD: standard diet; RE: resistance exercise; DIO: diet-induced obesity. 


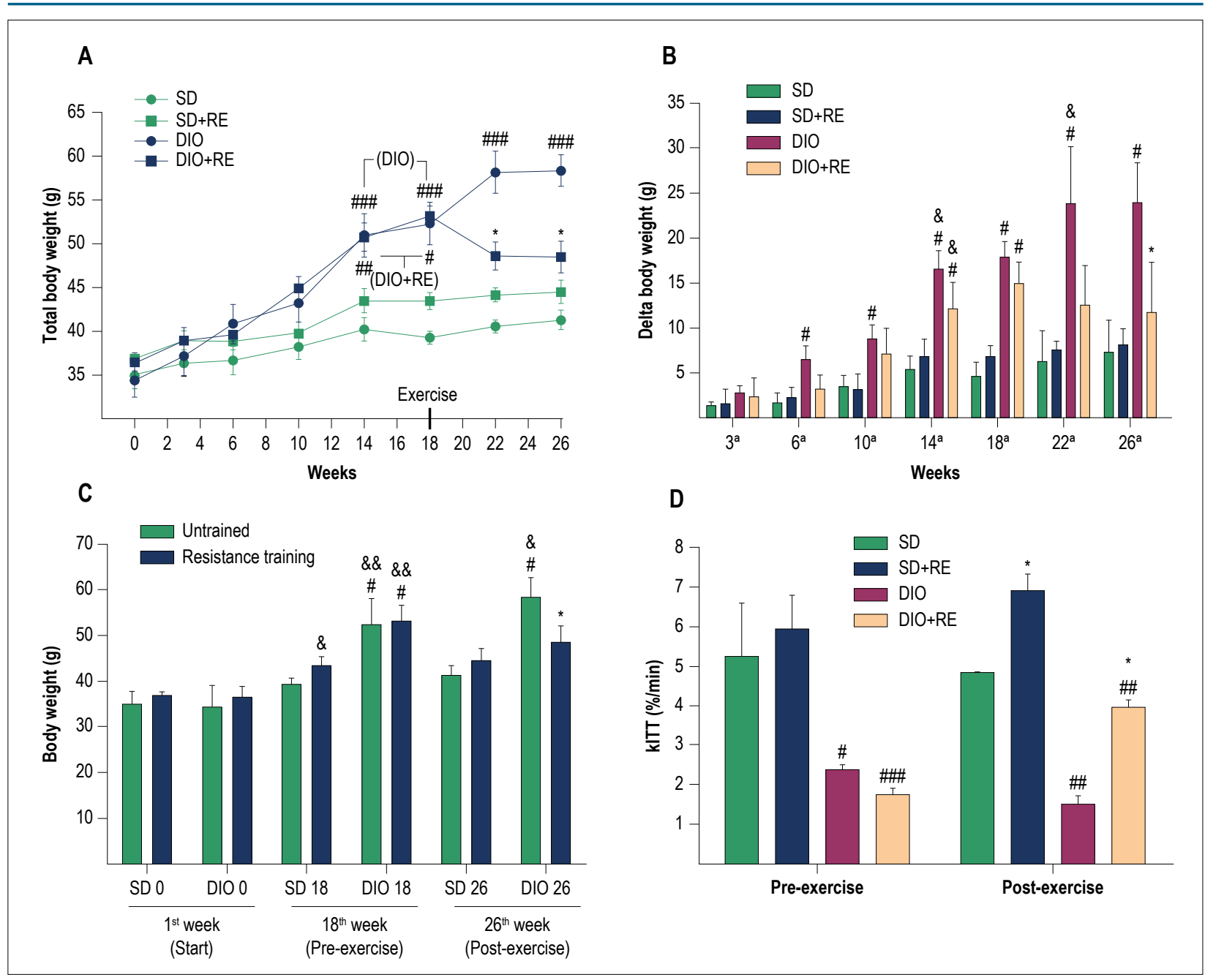

Figure 1 - A - Total body weight during the study; B - Delta (body weight variation in relation to the start of the study); $C$ - weight comparison between the 1 st week (start), $18^{\text {th }}$ week (pre-exercise) and $26^{\text {th }}$ week (post-exercise); $D$ - Glucose decay rate in the insulin tolerance test (kITT). Figure $A, B$ and $D-{ }^{*} p<0.05$ vs. respective untrained of the same period, ${ }^{\#} p<0.05,{ }^{\prime \prime} p<0.01$ and ${ }^{\# \#} p<0,001$ vs. respective $S D$ of the same period; ${ }^{*} p<0.05$ vs. same group of the previous week. Figure $C-{ }^{*} p<0.001$ vs. respective untrained of the same period; ${ }^{\#} p<0.01$ and ${ }^{\#} p<0.001$ vs. respective $S D$ of the same period; ${ }^{\&} p<0.05$, ${ }^{8} p p<0.001$ vs. same group of the previous week.

\section{CAT Activity}

The results observed in Figure 2D show a reduction in CAT activity in trained animals (SD + RE, $p<0.001$ and $\mathrm{SD}, \mathrm{DIO}+\mathrm{RE}, \mathrm{p}<0.01$ vs. untrained animals). On the other hand, the HFD animals also showed a decrease in CAT $(p<0.05)$, but only when compared to the SD animals.

\section{GSH}

Total glutathione levels were not significantly altered in both the interventions used in the present study (diet and exercise) (Figure 2E).

\section{Inflammatory Parameter}

The levels of TNF- $\alpha$ were used as an inflammatory indicator in cardiac tissue and the results observed in figure $2 \mathrm{~F}$ showed an increase in TNF- $\alpha$ content in DIO animals $(p<0.05)$, which was significantly reduced $(p<0.05)$ after the intervention with resistance physical exercise (DIO $+\mathrm{RE})$.

\section{Discussion}

Studies have shown that the consumption of a diet rich in fat, concomitant with a sedentary lifestyle, can trigger several health problems ${ }^{21,22}$ with a significant impact on the cardiovascular system. Therefore, experimental studies have been used to study the cellular effects of a high fat diet.6,23,24 The results of body weight and ITT showed that the adopted experimental model was effective in increasing weight and causing insulin resistance. Increased body weight has been associated to inflammatory changes and oxidative stress, and both these alterations to insulin resistance in skeletal muscle, ${ }^{25,26}$ but recent studies have also shown that cardiac cells are also susceptible to weight gain, by elevating inflammatory mediators and oxidative stress. ${ }^{6,23,24,27,28}$ In this context, previous studies suggested an important role of physical exercise, specifically aerobic or endurance, on the biochemical and molecular changes occurring in the myocardium as the result of a diet rich in fat. ${ }^{3,7}$ However, these effects depend on the characteristics of the exercise, such as duration, frequency, intensity and type. 


\section{Original Article}

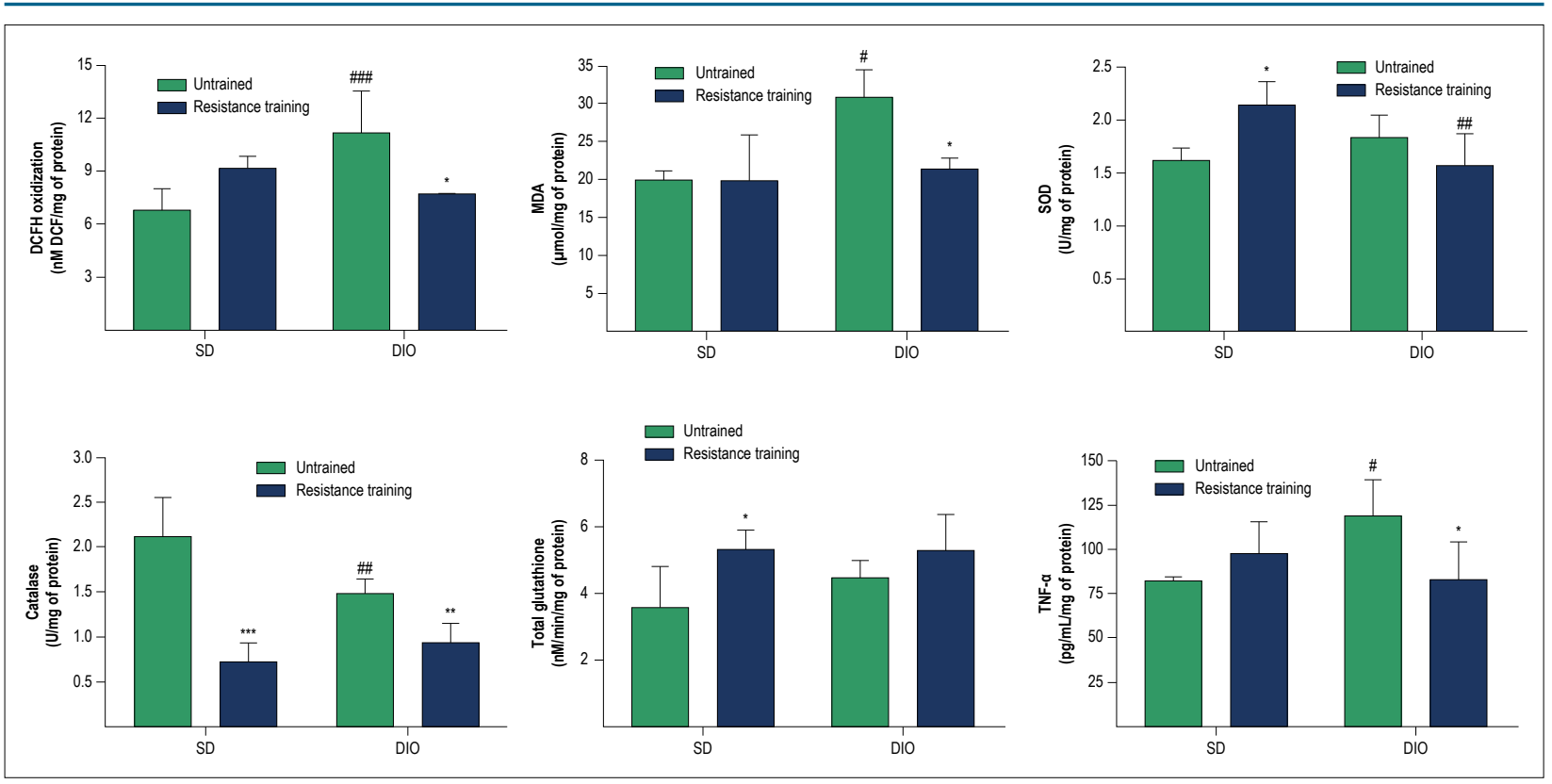

Figure 2 - Redox balance and inflammatory parameters in cardiac tissue of animals fed standard or high-fat diet and subsequently submitted to resistance training A - DCFH oxidation; $B$ - MDA content; $C$ - SOD enzyme activity; D - CAT enzyme activity; $E$ - Total glutathione content (reduced and oxidized); $F$ - levels of TNF-a. ${ }^{*} p<0.05,{ }^{* *} p<0.01$ and ${ }^{* * *} p<0.001$ vs. respective untrained; $\# p<0.05,{ }^{\#} p<0.01$ and ${ }^{\# \#} p<0.001$ vs. respective SD.

The initial results of our study show that DIO animals have elevated levels of DCF, an indirect indicator of hydrogen peroxide production. ${ }^{29}$ These data were also observed by a recent study published in 2017 by Zeng et al. ${ }^{23}$ The authors showed high myocardial susceptibility to oxidative stress, with a significant increase in DCFH oxidation, both in vitro and in vivo, mediated by a high-fat diet. These increased DCF values, observed in DIO animals, were significantly reduced after resistance training, which suggests an important role of this type of training in the regulation of cell oxidant levels. Such effect may be associated to the fact that resistance training has a modulatory role on endogenous antioxidant enzymes. This observation is based on previous studies of our group in other experimental models of inflammation, which show the important role of resistance training on the enzymatic antioxidant system in different tissues. ${ }^{30,31}$

SOD and CAT are two enzymes that act synergistically in the formation (via superoxide radical dismutation) and catalysis of hydrogen peroxide, respectively. DIO animals showed no changes in SOD activity, suggesting that an increased production of DCF may be associated with other stimuli independent from SOD. One of the factors responsible for it is that, although the oxidation of DCFH to DCF is widely used as an indicator of hydrogen peroxide production, studies have observed that DCFH can also be oxidized by other reactive species, on a smaller scale, such as hydroxyl, peroxyl, nitric oxide and peroxide nitrite. ${ }^{29}$ It is also noteworthy that the formation of hydrogen peroxide is not totally dependent on SOD activity. On a smaller scale, auto-oxidation events of biomolecules also contribute to the formation of hydrogen peroxide. ${ }^{32}$ These conditions would limit SOD activity, which may justify the results found.
Catalases constitute a group of enzymes that catalyze the decomposition of hydrogen peroxide into water and oxygen. Our results show a reduction in the activity of this enzyme after resistance training in the group exposed to SD. As observed, SOD activity was increased in this same group, thus generating higher levels of hydrogen peroxide. However, the decrease in enzyme activity suggests a lower hydrogen peroxide catalysis, but it is worth noting that hydrogen peroxide can be catalyzed under these conditions by other cell detoxification systems, such as glutathione and peroxins, ${ }^{33}$ which could justify our results since the glutathione system showed an increase in this group ( $\mathrm{SD}+\mathrm{RE}$ ). Furthermore, we observed reduced levels of CAT after resistance training in the DIO + RE group and, therefore, considering that the diet significantly increases the production of cell oxidants such as hydrogen peroxide, a reduced CAT activity could have an impact on the possible oxidative damages in the myocardium, if hydrogen peroxide were not catalyzed by other aforementioned systems (not investigated in the present study, although they deserve attention in future studies).

Aiming to observe the effects of RE on oxidative damage in the myocardium induced by the DIO model, we evaluated the levels of MDA, a byproduct of lipoperoxidation, and observed that DIO animals showed greater lipid damage in relation to the SD group and that the RE was able to reverse these effects. These effects of the DIO model on lipoperoxidation levels were also observed in a study with BL6/C57 mice performed by Muthulakshmi and Saravanan (2013). ${ }^{34}$ Positive RE results are possibly associated with the exercise capacity to promote the modulation of antioxidant systems, in addition to the activity of primary antioxidant enzymes such as SOD and CAT. One of the mechanisms 
that can be mediated by RE is the Nuclear Factor Erythroid 2 (NRF2) translocation to the nucleus and expression of several antioxidant enzymes such as $\mathrm{NADH}$ : quinone oxidoreductase 1 (NQO1) and Heme Oxygenase-1 (HO1). which help to detoxify the biological system and contribute to the reduction of oxidative stress. ${ }^{35}$ Merry and Ristow (2016) ${ }^{36}$ suggest that exercise may stimulate NRF2 translocation to functionally regulate mitochondrial biogenesis of skeletal muscle and the expression of antioxidants defense genes. Although these results are obtained from aerobic training and in skeletal muscle, it is believed that such effects may also occur via resistance training, as resistance training activates the Adenosine Monophosphate-Activated Protein Kinase $(\mathrm{AMPK})^{37}$, which enhances the phosphorylation of NRF2 in the cell and increases the level of phosphorylated NRF2 in the nucleus. ${ }^{38}$

The increased production of oxidants in the myocardium can be mediated by a possible inflammatory response induced by obesity/HFD with the secretion of different mediators. In this context, TNF- $\alpha$ is a mediator sensitive to the HFD model that shows a wide range of pro-inflammatory actions. Our results showed a significant increase in TNF- $\alpha$ levels in $\mathrm{DIO}$ animals with a consequent reduction after resistance training. Increased levels of TNF- $\alpha$ in the myocardium induced by a HFD have also been observed in previous studies., ${ }^{3,28}$ The effects of exercise may be related to the fact that aerobic and resistance exercises promote increased secretion of anti-inflammatory cytokines and regulate TNF- $\alpha$ levels. ${ }^{30,31}$ During the exercise, the muscles release myosins, which are involved in tissue growth, repair and anti-inflammatory responses. $.^{39} \mathrm{IL}-6$ is the primary myosin released in response to exercise and increases IL-10 and decreases TNF- $\alpha$ levels. ${ }^{40}$ IL-10 reduces cardiac dysfunction by decreasing cardiac fibrosis. ${ }^{39}$ In this scenario, HFD-induced obesity decreases IL-10 protein levels, but physical training significantly increases the IL-10 levels in cardiac tissues. ${ }^{3}$

According to data from previous studies, the control of TNF- $\alpha$ secretion in the myocardium by RE is considered an important factor in the cardioprotection mechanisms related to oxidative stress.

\section{Conclusion}

Our results showed an important effect of RE on the control/ stabilization of body weight even without food intake control. It was also demonstrated that there is a redox alteration in the cardiac tissue with an obesity model, but it does not seem to be mediated mainly by the classic antioxidant production and control of hydrogen peroxide, but rather by other reactive species. However, RE was able to reverse lipid damage and the production of reactive species, even with the consumption of a $\mathrm{HFD}$, as well as positively modulate one of the main cytokines responsible for the activation of the inflammatory process.

Therefore, RE can be a great ally in the health process regarding the therapeutic approach to obesity. Some limitations found in these studies were the data related to the quantification of serum insulin to better confirm insulin resistance, and the evaluation of other molecules that can alter the cell redox balance. These tests were not performed for technical reasons.

Finally, other studies should be performed aiming to better explain how RE promotes these effects, particularly in the regulation of reactive species such as hydroxyl, peroxyl, nitric oxide and peroxide nitrite, as well as other inflammatory and anti-inflammatory parameters in cardiac tissue.

\section{Author contributions}

Conception and design of the research: Ceddia RB, Pinho RA; Acquisition of data: Brescianini SMS, Fernandes BB, Fidelis GSP, da Silva PRL, Nesi RT; Analysis and interpretation of the data: Effting PS, Brescianini SMS, Silveira PCL, Nesi RT, Pinho RA; Statistical analysis: Effting PS, Silveira PCL, Pinho RA; Obtaining financing: Pinho RA; Writing of the manuscript: Effting PS, Pinho RA; Critical revision of the manuscript for intellectual content: Ceddia RB, Pinho RA.

\section{Potential Conflict of Interest}

No potential conflict of interest relevant to this article was reported.

\section{Sources of Funding}

This study was funded by CNPq and Capes.

\section{Study Association}

This article is part of the thesis of Doctoral submitted by Pauline Souza Effting, from Universidade do Extremo Sul Catarinense.

\section{Ethics approval and consent to participate}

This study was approved by the Ethics Committee on Animal Experiments of the Universidade do Extremo Sul Catarinense under the protocol number 067/2014-2.

\section{References}

1. WHO - World Healt Organization. Global Health Observatory $(\mathrm{GHO})$ data. Overweight and obesity [Internet]. Copenhagen: WHO; 2018 [citado 30 jul. 2018. Disponível em: http://www.who.int/gho/ncd/risk_factors/ overweight_obesity/obesity_adults/en/.

2. Fernández-Sánchez A, Madrigal-Santillán E, Bautista M, Esquivel-Soto J, Morales-González Á, Esquivel-Chirino C, et al. Inflammation, oxidative stress, and obesity. Int J Mol Sci. 2011;12(5):3117-32
3. Kesherwani V, Chavali V, Hackfort BT, Tyagi SC, Mishra PK. Exercise ameliorates high fat diet induced cardiac dysfunction by increasing interleukin 10. Front Physiol. 2015 Apr 22;6:124.

4. Sakurai T, Izawa T, Kizaki T, Ogasawara J, Shirato K, Imaizumi K, et al. Exercise training decreases expression of inflammation-related adipokines through reduction of oxidative stress in rat white adipose tissue. Biochem Biophys Res Commun. 2009;379(2):605-9. 
5. Adeghate E, Singh J. Structural changes in the myocardium during diabetesinduced cardiomyopathy. Heart Fail Rev. 2014;19(1):15-23.

6. Gamez-Mendez AM, Vargas-Robles H, Ríos A, Escalante B. Oxidative stressdependent coronary endothelial dysfunction in obese mice. PLoS One. 2015;10(9):e0138609.

7. Touati S, Montezano AC, Meziri F, Riva C, Touyz RM, Laurant P. Exercise training protects against atherosclerotic risk factors through vascular NADPH oxidase, extracellular signal-regulated kinase $1 / 2$ and stress-activated protein kinase/c-Jun N-terminal kinase downregulation in obese rats. Clin Exp Pharmacol Physiol. 2015;42(2):179-85.

8. Sharma NM, Rabeler B, Zheng H, Raichlin E, Patel KP. Exercise training attenuates upregulation of p47(phox) and p67(phox) in hearts of diabetic rats. Oxid Med Cell Longev. 2016;2016:5868913.

9. Boardman NT, Hafstad AD, Lund J, Rossvoll L, Aasum E. Exercise of obese mice induces cardioprotection and oxygen sparing in hearts exposed to high-fat load. Am J Physiol Circ Physiol. 2017;313(5):H1054-62.

10. Di Meo S, lossa S, Venditti P. Improvement of obesity-linked skeletal muscle insulin resistance by strength and endurance training. J Endocrinol. 2017;234(3):R159-81.

11. Hornberger TA Jr, Farrar RP. Physiological hypertrophy of the FHL muscle following 8 weeks of progressive resistance exercise in the rat. Can J Appl Physiol. 2004;29(1):16-31.

12. Scheffer DL, Silva LA, Tromm CB, da Rosa GL, Silveira PC, de Souza CT, et al. Impact of different resistance training protocols on muscular oxidative stress parameters. Appl Physiol Nutr Metab. 2012;37(6):1239-46.

13. Vilela TC, Effting PS, Dos Santos PG, Farias H, Paganini L, Rebelo SH, et al. Aerobic and strength training induce changes in oxidative stress parameters and elicit modifications of various cellular components in skeletal muscle of aged rats. Exp Gerontol. 2018 Jun; 106:21-7.

14. Ayala JE, Samuel VT, Morton GJ, Obici S, Croniger CM, Shulman Gl, et al. Standard operating procedures for describing and performing metabolic tests of glucose homeostasis in mice. Dis Model Mech. 2010;3(9-10):525-34.

15. Bradford MM. A rapid and sensitive method for the quantitation of microgram quantities of protein utilizing the principle of protein-dye binding. Anal Biochem. 1976 May 7;72:248-54.

16. Dong J, Sulik KK, Chen SY. The role of NOX enzymes in ethanolinduced oxidative stress and apoptosis in mouse embryos. Toxicol Lett. 2010;193(1):94-100

17. McCord JM, Fridovich I. Superoxide dismutase. An enzymic function for erythrocuprein (hemocuprein). J Biol Chem. 1969;244(22):6049-55.

18. Aebi H. Catalase in vitro. Methods Enzymol. 1984;105:121-6.

19. Hissin PJ, Hilf R. A fluorometric method for determination of oxidized and reduced glutathione in tissues. Anal Biochem. 1976;74(1):214-26.

20. Grotto D, Santa Maria LD, Boeira S, Valentini J, Charão MF, Moro $\mathrm{AM}$, et al. Rapid quantification of malondialdehyde in plasma by high performance liquid chromatography-visible detection. J Pharm Biomed Anal. 2007;43(2):619-24.

21. Barba I, Miró-Casas E, Torrecilla JL, Pladevall E, Tejedor S, Sebastián-Pérez R, et al. High-fat diet induces metabolic changes and reduces oxidative stress in female mouse hearts. J Nutr Biochem. 2017 Feb;40:187-93.

22 Carbone S, Mauro AG, Mezzaroma E, Kraskauskas D, Marchetti C, Buzzetti $\mathrm{R}$, et al. A high-sugar and high-fat diet impairs cardiac systolic and diastolic function in mice. Int J Cardiol. 2015 Nov 1;198:66-9.

23. Zeng C, Zhong P, Zhao Y, Kanchana K, Zhang Y, Khan ZA, et al. Curcumin protects hearts from FFA-induced injury by activating $\mathrm{Nrf} 2$ and inactivating NF-kB both in vitro and in vivo. J Mol Cell Cardiol. 2015 Feb;79:1-12.
24. Chen F, Chen D, Zhao X, Yang S, Li Z, Sanchis D, et al. Interleukin-6 deficiency facilitates myocardial dysfunction during high fat diet-induced obesity by promoting lipotoxicity and inflammation. Biochim Biophys Acta Mol Basis Dis. 2017;1863(12):3128-41.

25. Farias JM, Bom KF, Tromm CB, Luciano TF, Marques SO, Tuon T, et al. Effect of physical training on the adipose tissue of diet-induced obesity mice: interaction between reactive oxygen species and lipolysis. Horm Metab Res. 2013;45(3):190-6.

26. Pinho RA, Sepa-Kishi DM, Bikopoulos G, Wu M V., Uthayakumar A, Mohasses A, et al. High-fat diet induces skeletal muscle oxidative stress in a fiber type-dependent manner in rats. Free Radic Biol Med. 2017 Sep;110:381-9.

27. Pieri BL, Souza DR, Luciano TF, Marques SO, Pauli JR, Silva AS, et al. Effects of physical exercise on the P38MAPK/REDD1/14-3-3 pathways in the myocardium of diet-induced obesity rats. Horm Metab Res. 2014;46(9):621-7.

28. Farhangi MA, Nameni G, Hajiluian G, Mesgari-Abbasi M. Cardiac tissue oxidative stress and inflammation after vitamin $D$ administrations in high fat- diet induced obese rats. BMC Cardiovasc Disord. 2017;17(1):161.

29. Chen X, Zhong Z, Xu Z, Chen L, Wang Y. 2', $7^{\prime}$-Dichlorodihydrofluorescein as a fluorescent probe for reactive oxygen species measurement: forty years of application and controversy. Free Radic Res. 2010;44(6):587-604.

30. Tuon T, Souza PS, Santos MF, Pereira FT, Pedroso GS, Luciano TF, et al. Physical training regulates mitochondrial parameters and neuroinflammatory mechanisms in an experimental model of Parkinson's disease. Oxid Med Cell Longev. 2015;2015:261809.

31. Souza PS, Gonçalves ED, Pedroso GS, Farias HR, Junqueira SC, Marcon $\mathrm{R}$, et al. Physical exercise attenuates experimental autoimmune encephalomyelitis by inhibiting peripheral immune response and bloodbrain barrier disruption. Mol Neurobiol. 2017;54(6):4723-37.

32. Yi Y, Wang L, Li G, Guo H. A review on research progress in the direct synthesis of hydrogen peroxide from hydrogen and oxygen: noble-metal catalytic method, fuel-cell method and plasma method. Catal Sci Technol. 2016;6(6):1593-1610

33. Lennicke C, Rahn J, Lichtenfels R, Wessjohann LA, Seliger B. Hydrogen peroxide - production, fate and role in redox signaling of tumor cells. Cell Commun Signal. 2015 Sep 14;13:39.

34. Muthulakshmi S, Saravanan R. Protective effects of azelaic acid against highfat diet-induced oxidative stress in liver, kidney and heart of C57BL/6] mice. Mol Cell Biochem. 2013;377(1-2):23-33.

35. Done AJ, Traustadóttir T. Nrf2 mediates redox adaptations to exercise. Redox Biol. 2016 Dec;10:191-9.

36. Merry TL, Ristow M. Nuclear factor erythroid-derived 2-like 2 (NFE2L2, Nrf2) mediates exercise-induced mitochondrial biogenesis and the anti-oxidant response in mice. J Physiol. 2016;594(18):5195-207.

37. Williamson D, Gallagher P, Harber M, Hollon C, Trappe S. Mitogen-activated protein kinase (MAPK) pathway activation: effects of age and acute exercise on human skeletal muscle. J Physiol. 2003;547(Pt 3):977-87.

38. Joo MS, Kim WD, Lee KY, Kim JH, Koo JH, Kim SG. AMPK facilitates nuclear accumulation of Nrf2 by phosphorylating at serine 550. Mol Cell Biol. 2016;36(14):1931-42.

39. Petersen AMW, Pedersen BK. The anti-inflammatory effect of exercise. J Appl Physiol. 2005;98(4):1154-62.

40. Benatti FB, Pedersen BK. Exercise as an anti-inflammatory therapy for rheumatic diseases-myokine regulation. Nat Rev Rheumatol. 2015;11(2):86-97. 
